\title{
Prognostic Significance of Two Dimensional AgNOR Evaluation in Local Advanced Rectal Cancer Treated with Chemoradiotherapy
}

\author{
Mete Gundog ${ }^{1 *}$, Oguz G Yildiz ${ }^{1}$, Nalan Imamoglu² ${ }^{2}$ Dicle Aslan ${ }^{1}$,Aynur Aytekin ${ }^{3}$, \\ Isin Soyuer ${ }^{4}$, Serdar Soyuer ${ }^{1}$
}

\begin{abstract}
The prognostic significance of AgNOR proteins in stage II-III rectal cancers treated with chemoradiotherapy was evaluated. Silver staining was applied to the $3 \mu \mathrm{m}$ sections of parafin blocked tissues from 30 rectal cancer patients who received 5-FU based chemoradiotherapy from May 2003 to June 2006. The microscopic displays of the cells were transferred into the computer via a video camera. AgNOR area (nucleolus organizer region area) and nucleus area values were determined as a nucleolus organizer regions area/total nucleus area (NORa/ $\mathrm{TNa}$ ). The mean NORa/TNa value was found to be $9.02 \pm 3.68$. The overall survival and disease free survival in the high NORa/TNa (>9.02) patients were 52.2 months and 39.4 months respectively, as compared to 100.7 months and 98.4 months in the low $\mathrm{NORa} / \mathrm{TNa}(<9.02)$ cases. $(\mathrm{p}<0.001$ and $\mathrm{p}<0.001$ respectively). In addition, the prognosis in the high NORa/TNa patients was worse than low NORa/TNa patients $(p<0.05)$. In terms of overall survival and disease-free survival, a statistically significant negative correlation was found with the value of $\mathrm{NORa} / \mathrm{TNa}$ in the correlations tests. Cox regression analyses demostrated that overall survival and disease-free survival were associated with lymph node status (negative or positive) and the NORa/TNa value. We suggest that two-dimensional AgNOR evaluation may be a safe and usable parameter for prognosis and an indicator of cell proliferation instead of AgNOR dots.
\end{abstract}

Keywords: Two-dimensional AgNOR - chemoradiotherapy - morphometry - rectal cancer

Asian Pac J Cancer Prev, 16 (18), 8155-8161

\section{Introduction}

Colorectal cancer is a very common malignant tumor with about 1.2 million new cases and 600000 deaths worldwide each year (Raskov et al., 2014). The incidence of colorectal cancer in Turkey is 17.0 in men and 11.7 in women per 100000 persons (Eser et al., 2010). Several biologic markers, including allelic loss of $18 \mathrm{q}$, alteration in K-ras, MSI, thymidilate synthase, thymidine phosphorylase, vascular endothelial growth factor, epidermal growth factor receptor and P53, among others, are being prospectively evaluated in clinical trials to determine their prognostic utility in the colorectal cancer (Gunderson \& Teper, 2012, Clinical Radiation Oncology, third ed. Saunders, Philadelphia).

The Nucleolar Organizer Regions (NORs) are situated on the short arms of five pairs of human metaphase acrocentric chromosomes. The acidic proteins present in the NORs can be stained by using AgNOR or the silver staining technique and they are called AgNOR proteins.
During interphase, the NORs are nucleolus-associated and the AgNOR proteins situated in the fibrillar centers surrounding dense fibrillary components of the nucleoli (Ploton et al., 1986; Aubele et al., 1994; Trerè 1994). The interphase AgNOR protein quantity is a valuable indicator of the cellular activity and it is used to assess nucleolar activity and cell proliferation. In other words, an increase in the number and/or volume of AgNOR proteins is associated with an increase in cellular activity (Cabrini et al., 1992). Morphometric analysis of interphase AgNOR proteins in cancer cells has been utilized to detect differantial diagnosis of malignant versus benign cell and to indicate cancer prognosis as well as determine the proliferative activity of cells (Derenzeni et al., 1990; Losi et al.,1995; Gimenes-Mas J et al., 1995; Cücer et al., 2007; Khiavi et al., 2011). Although the correlation between AgNOR proteins and other proliferation markers (MIB 1/Ki-67, PCNA, p53) is uncertain, most authors are in agreement with AgNORs size and/or number being related to the proliferation activity (Nishi et al., 1994; Ofner et

${ }^{1}$ Departmentof Radiation Oncology, ${ }^{2}$ Department of Basic Pharmaceutical Sciences, ${ }^{4}$ Department of Pathology, ${ }^{3}$ Department of Radiation Oncology, Kayseri Education and Research Hospital, University of Erciyes, Kayseri, Turkey *For correspondence: mgundog@yahoo.com 
al., 1996; Öfner et al., 2000).

There was a little study related to morphometric analysis of AgNOR proteins in the patients with rectal cancer in literature. In this current study we aim to reveal the prognostic importance of AgNOR proteins on the patients with stage II-III rectal cancer who were treated with chemoradiotherapy. This is the first study that is available on the evaluation of prognosis in the patients with rectal cancer of morphometric analysis of AgNOR proteins as Nucleolus Organizer Regions area/Total Nucleus area $(\mathrm{NORa} / \mathrm{TNa})$.

\section{Materials and Methods}

\section{Study population}

This study includes 30 rectal cancer patients treated with 5-FU based chemotherapy and 50,4 Gy (1,8 Gy/day, 28 fractions) external beam radiotherapy to the pelvic lymph nodes and tumour beds from May 2003 to June 2006 at University of Erciyes, M.K. Dedeman Oncology Hospital. The histological classification of each case was evaluated by light microscopy according to American Joint Committe on Cancer (AJCC 2002) guidelines. The study protocol was approved by the local ethics committee. The

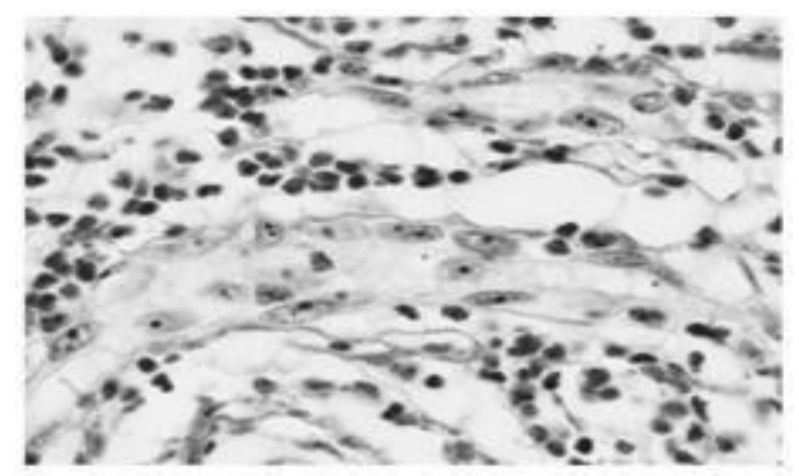

Figure 1. The Appearance of AgNOR Staining in the Rectal Cancer Cell (x100)

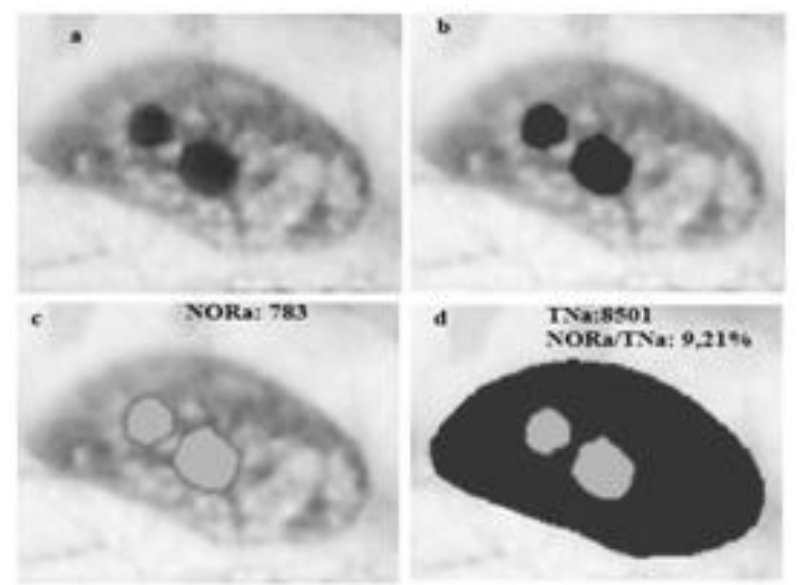

Figure 2. The image of Cell Nucleus Recorded into Computer for Analysis (a). The Determination of AgNOR Area (b). The Calculation of AgNOR Areas as NORa (NOR: 783) (c), The Calculation of total Nucleus Area as TNa $(\mathrm{TNa}=8501)$ and the Rates of the Calculated Values as NORa/TNa (NORa/TNa: 9.21\%) (d) study was conducted in accordance with the declaration of Helsinki and local laws depending on whichever afforded greater protection to the patients.

\section{Slide preparation and Giemsa and AgNOR staining}

The $3 \mu \mathrm{m}$ sections from each parafin embedded tumoral samples served as rectal cancer patient groups. After deparaffination and dehydration steps, the sections were stained with giemsa and AgNOR stainings. Giemsa and silver stainings of nucleolar organizer regionsassociated proteins (AgNORs) were performed according to Benn and Perle and Lindner prothocol no 2, respectively (Gordon, 1990; Linder 1993). The latter was used with a slight modification, the temperature was taken at $37{ }^{\circ} \mathrm{C}$ and the duration was diminished to $15 \mathrm{~min}$.

AgNOR staining was performed in the dark (in Petri dish enveloped with aluminum foils by dropping on the slides the solution made by mixing 1 vol. $2 \%$ gelatine in $1 \%$ aqueous formic acid and 2 vol. $50 \%$ silver nitrate (AgNO3), covered with coverslips and incubated at $37^{\circ} \mathrm{C}$ for $15 \mathrm{~min}$. After silver staining, the slides were rinsed, washed with bi-distilled water, coverslips were removed by itself during washing, and subsequently stained with 2 $\%$ Giemsa for $10 \mathrm{sec}$. The specimens were mounted with Entellan after 2 minutes of xylol treatment (Figure 1).

Table 1. Clinicopathological Characteristics of Patients according to NORa/TNa Value

\begin{tabular}{|c|c|c|c|c|}
\hline & Total & $\begin{array}{c}\text { Low NORa/ } \\
\text { TNa vaule } \\
(<9.02)\end{array}$ & $\begin{array}{c}\text { High NORa/ } \\
\text { Tna vaule } \\
(>9.02)\end{array}$ & p value \\
\hline Number of $p$ & ients $(\%)$ & $\mathrm{n}(\%)$ & $\mathrm{n}(\%)$ & $\mathrm{n}(\%)$ \\
\hline \multicolumn{5}{|c|}{ Age (year) } \\
\hline$<50$ & $9(30)$ & $5(55.6)$ & $4(44.4)$ & \multirow[t]{2}{*}{0.596} \\
\hline$\geq 50$ & $21(70)$ & $11(52.4)$ & $10(47.6)$ & \\
\hline \multicolumn{5}{|l|}{ Gender } \\
\hline Female & $12(40)$ & $6(37.5)$ & $6(42.9)$ & \multirow[t]{2}{*}{0.529} \\
\hline Male & $18(60)$ & $10(62.5)$ & $8(57.1)$ & \\
\hline \multicolumn{5}{|l|}{ Operation } \\
\hline AR & $5(16.7)$ & $2(12.5)$ & $3(21.4)$ & \multirow{3}{*}{0.332} \\
\hline LAR & $14(46.7)$ & $7(43.8)$ & $7(50)$ & \\
\hline APR & $11(36.7)$ & $7(43.8)$ & $4(28.6)$ & \\
\hline \multicolumn{5}{|c|}{ Depth of infiltration } \\
\hline $\mathrm{T} 3$ & $25(83.3)$ & $15(93.8)$ & $10(71.4)$ & \multirow[t]{2}{*}{0.126} \\
\hline $\mathrm{T} 4$ & $5(16.7)$ & $1(6.3)$ & $4(28.6)$ & \\
\hline \multicolumn{5}{|c|}{ Lymph node involvement } \\
\hline Negative & $18(60)$ & $11(68.8)$ & $7(50)$ & \multirow[t]{2}{*}{0.251} \\
\hline Positive & $12(40)$ & $5(31.3)$ & $7(50)$ & \\
\hline \multicolumn{5}{|c|}{ Vasculary invasion } \\
\hline+ & $8(26.7)$ & $5(31.3)$ & $3(21.4)$ & \multirow[t]{2}{*}{0.426} \\
\hline- & $22(73.3)$ & $11(68.8)$ & $11(78.6)$ & \\
\hline \multicolumn{5}{|c|}{ Perineural invasion } \\
\hline+ & $11(56.7)$ & $8(50)$ & $3(13.3)$ & \multirow[b]{2}{*}{0.107} \\
\hline- & $19(36.7)$ & $8(50)$ & $11(78.6)$ & \\
\hline \multicolumn{5}{|l|}{ Grade } \\
\hline 1 & $7(23.3)$ & $3(18.8)$ & $4(28.6)$ & \multirow{3}{*}{0.603} \\
\hline 2 & $16(53.3)$ & $10(62.5)$ & $6(42.9)$ & \\
\hline 3 & $7(23.3)$ & 3(18.8) & $4(28.6)$ & \\
\hline
\end{tabular}

American Joint Committe for Cancer Staging System (AJCC) 2002; $\mathrm{NORa/TNa}$; Nucleolus Organizer Regions area/Total Nucleus area; AR, anterior resection; LAR, low anterior resection; APR, abdominoperineal resection; $\mathrm{CI}$, confidence interval 


\section{Image analysis of AgNORs area}

The images of the analyzable nuclei transferred by means of a SONY CCD-IRIS.SSC-M370CE video camera and video capture card from Olympous BH-2 light microscope into a computer, and recorded. NORa/TNa proportions were calculated using the software designed specifically for this purpose (Demirtas et al., 2001). For NORa/TNa evaluation 100 consecutive cells were measured from each patient. The cells were photographed at 1000x magnification (Figure 2).

\section{Statistical analysis}

The statistical analysis of the data was performed by using IBM SPSS Statistics 22.0 (IBM Corp., Armonk, New York, USA). All the data was expressed as means \pm SD unless otherwise stated and controlled for normality using Shapiro-Wilk test. Chi-square analysis was used to compare categorical variables such as age, gender, type of operation, depth of infiltration, lymph node status, type of pathology, grade, vasculary and perineural invasion and AgNOR value. The correlation between the two parametric variables was calculated using the Pearson's correlation method. Kaplan-Meier analysis and log-rank tests were used for survival between groups. Differences were considered significant at $\mathrm{p}<0.05$.The effective

Table 2. Characteristics of Patients According to Disease-free Survival

\begin{tabular}{|c|c|c|c|}
\hline & $\begin{array}{l}\text { Number of } \\
\text { patients }(\%)\end{array}$ & $\begin{array}{l}\text { Survival months } \\
\quad(\% 95 \mathrm{CI})\end{array}$ & $\mathrm{p}$ value \\
\hline \multicolumn{4}{|l|}{ Age } \\
\hline$<50$ & $9(30)$ & $105.6(95.1-116.2)$ & \multirow[t]{2}{*}{0.185} \\
\hline$\geq 50$ & $21(70)$ & $96.8(88.8-104.8)$ & \\
\hline \multicolumn{4}{|l|}{ Gender } \\
\hline Female & $12(40)$ & $109.0(103.2-114.7)$ & \multirow[t]{2}{*}{0.206} \\
\hline Male & $18(60)$ & $97.1(88.8-105.3)$ & \\
\hline \multicolumn{4}{|l|}{ Operation } \\
\hline AR & $5(16.7)$ & $110.0(96.2-123.7)$ & \multirow[t]{3}{*}{0.318} \\
\hline LAR & $14(46.7)$ & $100.1(88.9-111.3)$ & \\
\hline APR & $11(36.7)$ & $97.6(87.4-107.8)$ & \\
\hline \multicolumn{4}{|c|}{ Depth of infiltration } \\
\hline $\mathrm{T} 3$ & $25(83.3)$ & $98.8(91.8-105.8)$ & \multirow[t]{2}{*}{0.182} \\
\hline $\mathrm{T} 4$ & $5(16.7)$ & $112.0(94.1-107.2)$ & \\
\hline \multicolumn{4}{|c|}{ Lymph node status } \\
\hline Negative & $18(60)$ & $98.9(90.6-107.2)$ & \multirow[t]{2}{*}{0.98} \\
\hline Positive & $12(40)$ & $106.3(103.0-109.6)$ & \\
\hline \multicolumn{4}{|c|}{ Vasculary invasion } \\
\hline+ & $11(56.7)$ & 89.0 (81.3- 96.7) & \multirow[t]{2}{*}{0.009} \\
\hline- & $19(36.7)$ & $105.3(98.4-112.1)$ & \\
\hline \multicolumn{4}{|c|}{ Perineural invasion } \\
\hline+ & $7(23.3)$ & $110.2(102.9-117.4)$ & \multirow[t]{2}{*}{0.006} \\
\hline- & $16(53.3)$ & $95.1(87.4-102,8)$ & \\
\hline \multicolumn{4}{|l|}{ Grade } \\
\hline 1 & $7(23.3)$ & $95.0(69.5-120.4)$ & \multirow{3}{*}{0.292} \\
\hline 2 & $13(43.3)$ & $103.8(96.3-111.2)$ & \\
\hline 3 & $17(56.6)$ & $89.5(76.7-102.2)$ & \\
\hline \multicolumn{4}{|l|}{$\mathrm{NORa} / \mathrm{TNa}$} \\
\hline$>9.02$ & $13(43.3)$ & $96.3(75.5-117.0)$ & \multirow[t]{2}{*}{0.703} \\
\hline$<9.02$ & $17(56.6)$ & $101.8(95.0-1108.5)$ & \\
\hline
\end{tabular}

American Joint Committe for Cancer Staging System (AJCC) 2002; NORa/TNa; Nucleolus Organizer Regions area/Total Nucleus area; AR, anterior resection; LAR, low anterior resection; APR, abdominoperineal resection; CI, confidence interval
DOI:http://dx.doi.org/10.7314/APJCP.2015.16.18.8155

Two-Dimensional AgNOR Evaluation in Rectal Carcinomas factors on overall survival and disease-free survival were analyzed using univarite and multivariete Cox regression models. Significant variables in the univariate analysis were included in the multivariate analysis and backwardwald method was used in order to determine the factors in the multivariate analysis. Removal probability for stepwise was taken $\mathrm{p}<0.10$.

\section{Results}

The median age of patients was 54 years (range; 26 -76 years). The mean follow-up time was 71.6 months. The overall survival and disease-free survival were 79 months and 71 months, respectively.The mean NORa/ $\mathrm{TNa}$ value was found as $9.02 \pm 3.68$. Table 1 shows clinicopathological characteristic of the patients according to the low AgNOR value and high AgNOR value. There was no significant difference between two groups in term of age, gender, type of operation, depht of infiltration, lymph node involvement, vasculary and perineural invasion. Table 2 shows the disease-free survival according to characteristics of the patients. Only vasculary and perineural invasion significantly influenced the disease-free survival (p: 0.009 and p: 0.006, respectively).

Table 3 shows the overall survival according to

Table 3. Characteristics of Patients According to Overall Survival

\begin{tabular}{|c|c|c|c|}
\hline & $\begin{array}{l}\text { Number of } \\
\text { patients (\%) }\end{array}$ & $\begin{array}{l}\text { Survival months } \\
\quad(\% 95 \mathrm{CI})\end{array}$ & $\mathrm{p}$ value \\
\hline \multicolumn{4}{|l|}{ Age } \\
\hline$<50$ & $9(30)$ & $105.6(95.1-116.2)$ & \multirow[t]{2}{*}{0.193} \\
\hline$\geq 50$ & $21(70)$ & $97.0(89.0-105.0)$ & \\
\hline \multicolumn{4}{|l|}{ Gender } \\
\hline Female & $12(40)$ & $109.0(103.2-114.7)$ & \multirow[t]{2}{*}{0.215} \\
\hline Male & $18(60)$ & $97.4(89.3-105.6)$ & \\
\hline \multicolumn{4}{|l|}{ Operation } \\
\hline AR & $5(16.7)$ & $110.0(96.2-123.7)$ & \multirow{3}{*}{0.293} \\
\hline LAR & $14(46.7)$ & $100.1(88.9-111.3)$ & \\
\hline APR & $11(36.7)$ & $97.6(87.4-107.8)$ & \\
\hline \multicolumn{4}{|c|}{ Depth of infiltration } \\
\hline $\mathrm{T} 3$ & $25(83.3)$ & $98.8(91.8-105.8)$ & \multirow[t]{2}{*}{0.165} \\
\hline $\mathrm{T} 4$ & $5(16.7)$ & $112.0(102.2-121.8)$ & \\
\hline \multicolumn{4}{|c|}{ Lymph node status } \\
\hline Negative & $18(60)$ & $98.9(90.6-107.2)$ & \multirow[t]{2}{*}{0.928} \\
\hline Positive & $12(40)$ & $106.3(103.0-109.6)$ & \\
\hline \multicolumn{4}{|c|}{ Vasculary invasion } \\
\hline+ & $8(26.7)$ & $89.0(81.3-96.7)$ & \multirow[t]{2}{*}{0.008} \\
\hline- & $22(73.3)$ & $105.5(98.9-112.1)$ & \\
\hline \multicolumn{4}{|c|}{ Perineural invasion } \\
\hline+ & $11(56.7)$ & $110.2(102.9-117.4)$ & \multirow[t]{2}{*}{0.007} \\
\hline- & $19(36.7)$ & $95.5(88.0-103.0)$ & \\
\hline \multicolumn{4}{|l|}{ Grade } \\
\hline 1 & $7(23.3)$ & $95.0(69.5-120.4)$ & \multirow{3}{*}{0.351} \\
\hline 2 & $16(53.3)$ & $103.8(96.3-111.2)$ & \\
\hline 3 & $7(23.3)$ & 89.5 (76.7- 102.2) & \\
\hline \multicolumn{4}{|l|}{ NORa/TNa } \\
\hline$>9.02$ & $13(43.3)$ & $98.1(77.6-118.6)$ & \multirow[t]{2}{*}{0.651} \\
\hline$<9.02$ & $17(56.6)$ & $101.8(95.0-108.5)$ & \\
\hline
\end{tabular}

American Joint Committe for Cancer Staging System (AJCC) 2002; NORa/TNa; Nucleolus Organizer Regions area/Total Nucleus area; AR, anterior resection; LAR, low anterior resection; APR, abdominoperineal resection; $\mathrm{CI}$, confidence interval 


\section{Mete Gundog et al}

characteristic of the patients. Similarly, vasculary and perinural invasion significantly influenced the overall survival (p: 0.008 and p: 0.007, respectively).

In the Pearson correlation test, a statistically significant negative correlation was found between the $\mathrm{NORa} / \mathrm{TNa}$ value and disease-free survival (p: 0.001, Figure: 3), similarly there was a statistically significant negative correlation between the NORa/TNa value and overall survival ( $<<0.05$, Figure: 4$)$.

The patients with havig the NORa/TNa value less than 9.02 was called as low NORa/TNa group. Likewise the patients with having the NORa/TNa value more than 9.02 were called as high NORa/TNa group. The overall survival was found to be 52.21 months in the high $\mathrm{NORa} / \mathrm{TNa}$ group while the overall survival was found to be 100.69 months in the low NORa/TNa group. The disease-free survival was found to be 39.14 months in the high NORa/TNa group while disease-free survival was

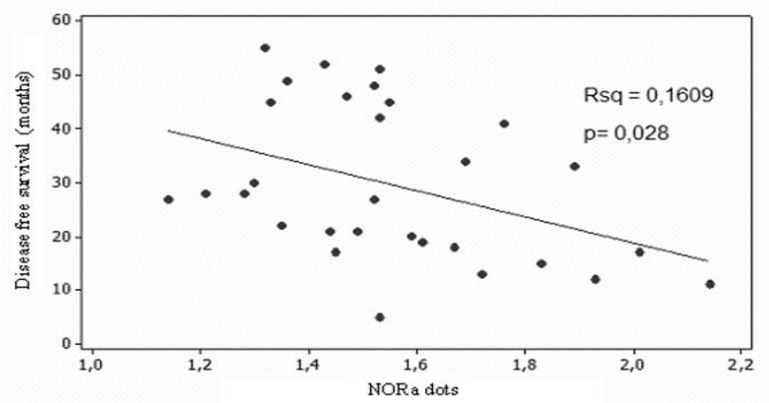

Figure 3. Correlation Between NORa/TNa and Disease-free Survival

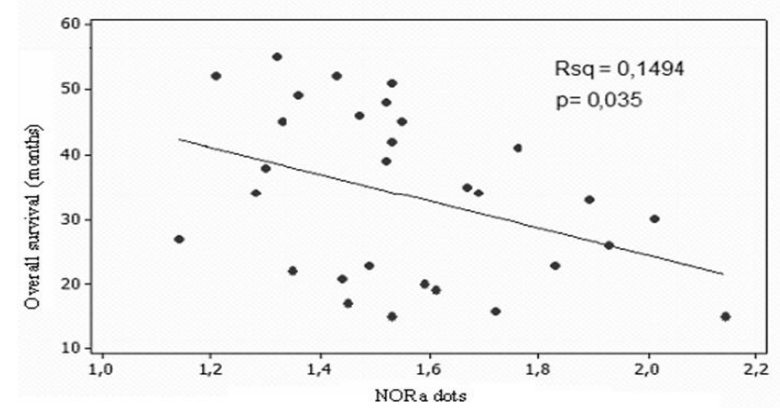

Figure 4. Correlation Between NORa/TNa and Overall Survival found 98.38 months in the low NORA/TNa group. There was a statistically significant difference that was found between the two groups in point of disease-free survival and overall survival (p: 0.001 Figure 5, p: 0.001 Figure 6 , respectively).

Univariete and multivariete analyses were performed to identify the risk factors related the disease-free survival (Table 4). Lymph node status, type of pathology and NORa/TNa value differed significantly between these groups in univariate analyses for disease-free survival (p: 0.055 , p: 0.007 and p: 0.002 , respectively). All of these variables were included in the multivariate analyses. Cox regresion analyses demostrated that the disease-free

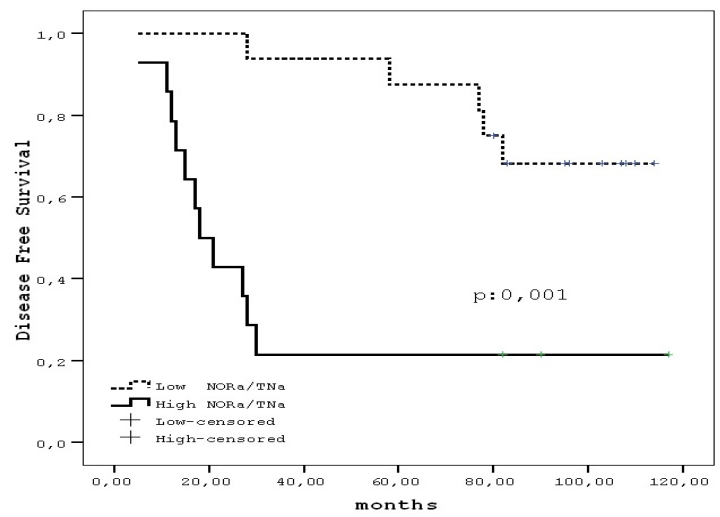

Figure 5. Disease Free Survival Curve of NORa/TNa values Between Groups

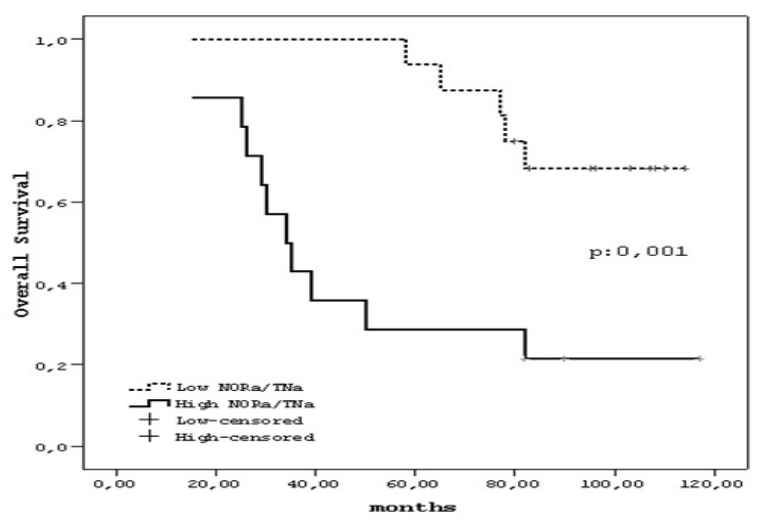

Figure 6. Overall Survival Curve of NORa/TNa values Between Groups

Table 4. Univariate and Multivariate Analysis of Risk Factors for Disease-free Survival

\begin{tabular}{|c|c|c|c|c|}
\hline \multirow[b]{2}{*}{ Risk factor } & \multicolumn{2}{|l|}{ Univariate } & \multicolumn{2}{|c|}{ Multivariate } \\
\hline & $\mathrm{OR}(95 \% \mathrm{CI})$ & $\mathrm{p}$ value & $\mathrm{OR}(95 \% \mathrm{CI})$ & $\mathrm{p}$ value \\
\hline Age $(\geq 50$ years or $<50$ years $)$ & $1.013(0.972-1.056)$ & 0.528 & & \\
\hline Gender (female or male) & $1.775(0.664-4.743)$ & 0.253 & & \\
\hline Type of operation (AR/LAR or APR) & $1.287(0.307-5.390)$ & 0.730 & & \\
\hline Depth of infiltration (T3 or T4) & $1.448(0.412-5.087)$ & 0.564 & & \\
\hline Lymph node metastasis (negative or positive) & $2.635(0.978-7.102)$ & 0.055 & $2.921(1.032-8.267)$ & 0.044 \\
\hline Type of pathology (adenocarcinoma or signet ring cell ) & $2.112(1.633-22.877)$ & 0.007 & $1.468(0.324-6.644)$ & 0.618 \\
\hline Vasculary invasion & $0.954(0.307-2.961)$ & 0.934 & & \\
\hline Perineural invasion & $0.868(0.315-2.392)$ & 0.784 & & \\
\hline Grade & $0.445(0.135-1.465)$ & 0.183 & & \\
\hline $\mathrm{NORa} / \mathrm{TNa}$ value $(>9.02$ or $<9.02)$ & $5.555(1.881-16.405)$ & 0.002 & $6.108(1.980-18.843)$ & 0.002 \\
\hline
\end{tabular}

American Joint Committe for Cancer Staging System (AJCC) 2002; NORa/TNa; Nucleolus Organizer Regions area/Total Nucleus area; OR; odds ratio, AR: Anterior resection, LAR: Low anterior resection, APR: Abdominoperineal resection 
Table 5. Univariate and Multivariate Analysis of Risk Factors for Overall Survival

\begin{tabular}{|c|c|c|c|c|}
\hline \multirow[b]{2}{*}{ Risk factor } & \multicolumn{2}{|l|}{ Univariate } & \multicolumn{2}{|c|}{ Multivariate } \\
\hline & $\mathrm{OR}(95 \% \mathrm{CI})$ & $\mathrm{p}$ value & $\mathrm{OR}(95 \% \mathrm{CI})$ & $\mathrm{p}$ value \\
\hline Age ( $\geq 50$ years or $<50$ years) & $1.015(0.973-1.058)$ & 0.496 & & \\
\hline Gender (female or male) & $1.706(0.637-4.569)$ & 0.288 & & \\
\hline Type of operation (AR/LAR or APR) & $1.157(0.276-4.850)$ & 0.852 & & \\
\hline Depth of infiltration (T3 or T4) & $1.304(0.370-4.597)$ & 0.679 & & \\
\hline Lymph node metastasis (negative or positive) & $2.630(0.977-7.080)$ & 0.056 & $2.692(0.993-7.297)$ & 0.052 \\
\hline Type of pathology (adenocarcinoma or signet ring cell ) & $3.697(1.043-13.103)$ & 0.043 & $0.655(0.136-3.149)$ & 0.597 \\
\hline Vasculary invasion & $0.951(0.306-2.950)$ & 0.930 & & \\
\hline Perineural invasion & $0.884(0.321-2.437)$ & 0.812 & & \\
\hline Grade & $0.431(0.131-1.423)$ & 0.167 & & \\
\hline $\mathrm{NORa} / \mathrm{TNa}$ value $(>9.02$ or $<9.02)$ & $5.058(1.726-14.825)$ & 0.003 & $5.188(1.755-15.337)$ & 0.003 \\
\hline
\end{tabular}

American Joint Committe for Cancer Staging System (AJCC) 2002; NORa/TNa; Nucleolus Organizer Regions area/Total Nucleus area; OR; odds ratio, AR: Anterior resection, LAR: Low anterior resection, APR: Abdominoperineal resection

survival associated with lymph node status (negative or positive) and the NORa/TNa value $(<9.02$ or $>9.02)$, (p: 0.044 and p: 0.002 respectively). Univariete and multivariete analyses were performed to identify the risk factors related overall survival also (Table 5). Similarly, the lymph node status, type of pathology and NORa/ $\mathrm{TNa}$ value differed significantly between these groups in univariate analyses for overall survival (p: 0.056, p: 0.043 and p: 0.003 respectively). Cox regresion analyses demostrated that overall survival was associated with lymph node status (negative or positive) and the NORa/ TNa value (<9.02 or $>9.02)$, (p: 0.052 and p: 0.003 respectively).

\section{Discussion}

The NORs have a central importance in regulation of protein synthesis in the cell, and also size and number give information about the cell proliferation rate as well as during malignancy transformation may vary. In the AgNOR analysis, visual observation is said to be a subjective method whereas agnor area analysis is more realistic and beneficial (Wai et al., 2000; Chen et al., 2003). Agnor can be accepted as a determinant for prognosis. When it is compared with different prognostic factors, AgNOR has an important statistical value that allows patients to be divided into different risk groups (Pich et al., 2000).

The other study in the literature point out that this method can not be related to the prognostic factors alone in their study evaluating the NORa number. They couldn't find any relationship between the NORa dots and survival. But they found a correlation between the NORa number and tumour differentiation and they pointed out that it is reliable for identifying adenoma from colorectal carcinoma (Eminovic et al., 2000).

In the study of Losi L et al. (Losi et al., 1995), on patients having colorectal cancer, the cell proliferation is not seen as a direct parameter and also they define the NORa dots value as for being a determinant for cell proliferation. In the study Adachi et al. (Adachi et al., 1995), on 60 patients having colorectal cancer, the NOR dots and flow cytometric DNA analysis are compared. DNA index is related to invasion depth and lymph node metastasis but there isn't any correlation found with NORa number. In another study in which, 64 patients having colorectal cancer in stage II-IV taking chemotheraphy based on 5-FU, divides the patients as two groups NOR area smaller (low-risk group) than $4.8 \mu \mathrm{m}^{2}$ and NOR area bigger (high-risk group) than $4.8 \mu \mathrm{m}^{2}$. There is a relapse seen in 2 of 24 low-risky group patients whereas there is a relapse in 10 of 23 high-risk group patients and there is statistically significant difference between two groups. 17 patients in stage IV are evaluated after a 12 months observation. In the high-risk group, 10 patients die whereas in the low-risk group all the patients survive (Öfner et al., 2000). In another study, the patients are divided into two groups called the NORa dots less than 3.83 as the low NORa group and higher than 3.83 as the high NOR group. When their overall survivals are compared, there is a statistical difference between them. Again, among the NORa dots and the invasion depth, peritoneal metastasis and liver metastasis there is a positive correlation found (Nakea et al., 1998).

In this study where the rate of NOR area is evaulated to the cell nucleus, the mean NORa/TNa value is found as $9.03 \pm 3.68$. The patients having the NORa/TNa value less than 9.02 are called as low NORa/TNa group. The patients having the NORa/TNa value more than 9.02 are called as high NORa/TNa group. In this present study we demostrated that statistically significant difference was found between the overall survival and the disease-free survival among the groups when analysed by KaplanMeier test.

In the literature, there were no any correlation between count of NOR dots and vasculary invasion and between perinoral invasion and NORa dots in the patients with colorectal carcinoma (Nishi et al., 1994; Nakae et al., 1998; Öfner et al., 2000). In our study, there were no any statistically significant correlation found between NORa/ $\mathrm{TNa}$ and vascular invasion $(\mathrm{p}=0.426)$ and between NORa/ $\mathrm{TNa}$ and perinoral invasion ( $\mathrm{p}=0.107)$. In the same studies have been shown that there is no significant correlation between lenf node metastasis and NOR dots. In our study, between NORa/TNa and lymph node metastasis the correlation is resarched but there was no statistical correlation found $(\mathrm{p}=0.251)$.

When the NORa dots are thought as prognostic factor the results are controversial in the literature. This is the first study in which the NORa/TNa value is used in the 
literature for colorectal cancer. In this study for NOR regions and $\mu \mathrm{m}^{2}$ area values evaluted. This morphometric study was conducted as a $\%$ value that form regions of the NOR area proportioned the same as the nucleus area (NORa/TNa).

NOR proteins increasing in tumour cell are related to protein synthesis in ribosomes and also DNA regions being too active. These proteins can have some roles in activating the tumour, increasing invasion capability and the potential of forming metastasis. In AgNOR analysis, counting the silver-stained dots under the light microscope has a number of limitations. Simply enumerating each silver-stained dot per cell under the microscope is subjective and poorly reproducible. This limitation becomes serious when single AgNOR dots are clustered together or partially overlapped. Furthermore, counting alone does not take into consideration the size of each silver-stained dot, which is variable. Inter-observation variation is also a problem in the routine method. These limitations were circumvented by means of computerassisted measurement of NORa/TNa proportion. This situation can define worse prognosis in the tumours having a large NOR area.

In conclusion, we have suggested that two-dimensional AgNOR evaluation may be a safe and usable parameter for prognosis and indicator of cell proliferation instead of AgNOR dots. As a pilot study with a limited number of patients, our data have shown that two-dimensional AgNOR evaluation (Nucleolus Organizer Regions area/ Total Nucleus area per cell) may be used as a prognostic factor in the patients with rectal cancer. However, we need further trials with large number of patients.

\section{Acknowledgements}

This work was supported by EURF (Erciyes University Research Fund; Contract grant number TT-07-49).

\section{References}

Adachi Y, Kido A, Mori M, et al (1995). Nucleolar DNA content and nucleolar organizer regions in colorectal cancer. J Surg Oncol, 59, 177-80

Aubele M, Biesterfeld S, Derenzini M, et al (1994). Guidelines of AgNOR quantitation. Zentralbl Pathol, 140, 107-8

Boring CC, Squires, Tong T (1993). Cancer Statistics. CA Cancer J Clin, 43, 7-26

Cabrini R, Schwint A, Méndez A, et al (1992). Morphometri study of nucleolar organizer regions in human oral normal mucosa, papilloma and squamous cell carcinoma. J Oral Pathol Med, 21, 257-9.

Chen Maohuai MD, CK Lee J, Lo S (2003). Argyrophilic Nuclear Organizer Regions in Nasopharyngeal Carsinoma and Paraneoplastik Epithelia. Head Neck, 25, 395-9

Chern JH, Lee YC, Yang MH, et al (1997). Usefulness of AgNOR score in differentiating bening from malignant pulmonary aspiration cytology. Acta Cytol, 41, 393-8

Cucer N, Imamoglu N, Tozak H, et al (2007). Two-dimensional agnor evaluation as a prognostic variable in urinary bladder carcinoma, a different approach via total agnor area/nucleus area per cell. Micron, 38, 674-9

Demirtas H, Imamoglu N, Donmez H, et al (2001). Condensed chromatin surface and NORs surface enhancement in mitogen-stimulated lymphocytes of Down syndrome patients. GenParis, 44, 77-82.

Derenzini M, Nardi F, Farabegoli F, et al (1989). Disrubition of silver-stained interphase nucleolar organizer regions as a parameter to distinguish neoplastic from nonneoplastic reactive cell in human effusions. Acta Cytol, 33, 491-8

Derenzini M, Pession A, Treré D (1990). Quantity of nucleolar silver-stained proteins is related to proliferating activity in cancer cells. Lab Invest. 63, 137-40

Derenzini M, Romagnoli T, Mingazzini P, et al (1988). Interphasic nucleolar organizer region distribution as a diagnostic parameter to differentiate bening from malignant epithelial tumors of human intestine. Virchows Arch, 54, 334-40

Derenzini M, Treré D, Mambelli V, et al (1990). Diagnostic value of silver-stained interphasic nucleolar organizer in the breast tumors. Ultrastruct Pathol, 14, 233-45

Eser S, Yakut C, Özdemir R, et al (2010). Cancer incidence rates in Turkey in 2006. Asian Pac J Cancer, 11, 1731-9

Fonseca I, Soares J (1993). Adenoid cystic carcinoma a study of nucleolar organizer regions (AgNORs) counts and their relation to prognosis. J Pathol, 169, 255-258

Gimenes-Mas J, Gallego-Calvo P, Sanz-Moncasi P, et al (1995). AgNOR evaluation by image processing methods. Staining modifications and results in 126 invasive ductal breast carsinomas. Anal Quant Cytol Histol, 18, 9-18

Gordon K.C, Bancoft JD, Stevens A, et al Turner DR (Eds) (1990). Theory and practise of histological tecniques. 3rd ed. Churchill Livingstone, London.

Gunderson \& Teper (2012). Clinical radiation oncology (3th edition) Saunders, Philadelphia, pp. 1113-1114

Lindner LE (1993). Improvements in the silver-staining technique for nucleolar organizer regions (AgNOR). $J$ Histochem Cytochem, 41, 439-445

Losi L, DiGregorio C, Fante R, et al (1995). Argyrophilic nucleolar organizer regions and bromodeoxyuridine and $3[\mathrm{H}]$-thymidine labelling indices in colorectal cancer. Cell Prolif, 28, 471-80

Nishi Y, Takano Y, Kakita A (1994). Analyses of PCNA and AgNOR on advanced colorectal cancer as predictive indicators of the prognosis. Nippon Geka Gakkai Zasshi, 95, 797-806

Öfner (2000). In situ standardised AgNOR analysis, a simplified method for routine use to determine prognosis and chemthrapy efficiency in colorectal adenocarcinoma. Micron, 31, 161-4

Öfner D, Bier B, Heinrichs S, et al (1996). Demonstration of silver-stained nucleolar organizer region associated proteins (AgNORs) after wet autoclave pretreatment in breast carsinoma, correlation to tumour stage and long-term survival. Breast Cancer RES Treat, 39, 165-76

Öfner D, Tötsch M, Sandbicher P, et al (1990). Silver stained nucleolar organizer regions (Ag-NORs) as a predictor of prognosis in colonic cancer. $J$ Pathol, 162, 43-49

Pich A, Chiusa L, Margaria E (2000). Prognostik relevance of AgNORs in tumor pathology. Micron, 31, 133-141

Piffko J, Bankfalvi A, Öfner D, et al (1997). Prognostic value of histobiological factors (malignancy grading and AgNOR content) assessed at the invasive tumor front of oral squamous cell carsinomas. Br J Cancer, 75, 1543-6

Piffko J, Bankfalvi A, Öfner D, et al (1997). Standardized demonstration of silver-stained nucleolar organizer regions, associated proteins in archival oral squamous cell carsinomas and adjacent non-neoplastic mucusa. Mod Pathol, 10, 98-104

Ploton D, Menager M, Jeannneson P, et al (1986). Improvement in staining and in the visualization of the argyrophilic proteins of the nucleolar organizer region at the optical level. 
Histon chem $J, \mathbf{1 8}, 5-14$

Raskov H, Pommergand HC, Burcharth J, et al (2014). Colorectal carcinogenesis update and perspective. World $J$ Gastroenterol, 20, 18151-64

Senija Eminović-Behrem, Zlatko Trobonjača, Mladen Petrovečki, et al (2000). Prognostic significance of dna ploidy pattern and nucleolar organizer regions(AgNOR) in colorectal cancer. Croatian Medical Journal, 41, 154-8

Shiro Nakae, Takeshi Nakamura, Ryuichiro Ikegawa, et al (1998). Evaluation of argyrophilic nucleolar organizer region and proliferating cell nuclear antigen in colorectal cancer. $J$ Surgical Oncol, 69, 28-35

Sideris M, Papagrigoriadis S (2014). Molecular biomarkers and classification models in the evaluation of the prognosis of colorectal cancer. Anticancer Res, 34, 2061-8

Suto T, Sugai T, Nakamura S, et al (1998). Assessment of the expression of p53, MIB-1 (Ki-67 antigen) and argyrophilic nucleolar organizer regions in carsinoma of the extrahepatic bile duct. Cancer, 82, 86-95

Treré D (1994). Technical and methodological aspects of silver staining and measurement of nucleolar organizer region (NOR). Zentralbl Pathol, 140, 11-14

Treré D, Farabegoli F, Cancellieri A, et al (1991). AgNOR area in interphase nuclei of human tumours correlates with the proliferative activity evaluated by bromodeoxyuridine labelling and KI-67 immunostaining. J Pathol, 165, 53-59

Treré D, Pession A, Derenzini M (1989). The silver stained proteins of interphasic nucleolar organizer regions as a parameter of cell duplication rate. Exp Cell Res, 184, 131-7

Wai Pak M, Fai To K, Huai Chen M, et al (2000). Morphometricanalysis of argyrophilic nucleolar organizer regions (AgNORs) in Nasopharyngeal Carsinoma. Head Neck, 22, 760-4 